\title{
Motion events in Afrikaans: their expression by adult speakers and by children with and without language impairment
}

\author{
Helena Oosthuizen and Barbara Höhle \\ Department of Linguistics, University of Potsdam, 14476 Potsdam, Germany \\ Frenette Southwood \\ Department of General Linguistics, Stellenbosch University, 7600 Stellenbosch, South Africa \\ E-mail: fs@sun.ac.za
}

\begin{abstract}
Motion events occur frequently in everyday life as people and objects constantly change their relative location to one another. Although children's descriptions of motion events resemble those of adults in their own language group from very early on (Choi and Bowermann 1991), there is increasing evidence for subtle differences as well. Young children speaking different languages seem to have some difficulty in expressing two types of spatial information in the same conceptual frame (e.g. Ochsenbauer and Hickmann 2010). In English and other satellite-framed languages such as German and Afrikaans, this task involves using a complex particle verb construction in which a directional particle (e.g. out) combines with a prepositional phrase carrying further information about the source or goal of movement (e.g. some bees came out of the tree) (Berman and Slobin 1994:161). Little is known about the development of this type of structure in satellite-framed languages such as Afrikaans. This paper examined whether (i) there are developmental differences between adults and 6-year-old Afrikaans-speaking children in the production of preposition+verb particle structures, and whether (ii) children with language impairment produce these structures in a different way than typically developing children. Target elements were preposition+verb particle structures with the particles af 'down', in 'in', uit 'out' and $o p$ 'up'. The performance of ten adults was compared to that of 30 typically developing and three language-impaired 6-year-olds. Half of the participants in the adult and typically developing groups were speakers of Mainstream Afrikaans (MA), and half were speakers of Cape Afrikaans (CA), a non-mainstream dialect. Distinct developmental differences that could not be attributed to dialectal variation, were found between 6-year-olds and adults. Children with language impairment showed less variation in their responses than their typically developing peers. Possible explanations for the findings are discussed.
\end{abstract}

Keywords: Afrikaans, Cape Afrikaans, spatial language, dialectal variation, language disorder

\section{Introduction}

Motion events are those in which an entity moves from one location to another. Such events can be analyzed as consisting of the following main semantic components: (i) Figure, viz. the physical entity that is moving, (ii) Ground, viz. the point in space in relation to which the 
Figure moves, (iii) Path (in the sense used by Talmy 2000), viz. the direction and route followed by the moving entity with respect to the Ground and (iv) Manner, i.e. the way in which movement takes place. Sentence (1) illustrates how these basic components might be expressed in English:

The apple rolled off the table.

Figure Manner Path Ground

According to Talmy (2000), languages can be grouped into two main typologies based on the way information about Path and Manner is "packaged": Verb-framed languages (e.g. French, Korean) typically express information about Path in the main verb (e.g. French monter 'to go up'), with Manner mostly being expressed by means of peripheral markings (e.g. subordinate clauses and adverbial expressions). Satellite-framed languages such as English, German and Afrikaans, in contrast, typically express information about Manner in the verb, and about Path by means of so-called "satellites" (e.g. English go up; German nach oben gehen lit. 'to above go'). This term encompasses a number of different grammatical forms - e.g. English verb particles, and German separable and inseparable verb prefixes - employed by different languages to express information about Path. In the rest of the paper, we examine one type of satellite used in Afrikaans, namely, verb particles. We consider its use by adult speakers as well as by children with and without language impairment.

\subsection{Expressing motion events in Afrikaans \\ 1.1.1 Particle verbs in Afrikaans}

Direction is often ${ }^{1}$ expressed in Afrikaans by means of a spatial verb particle such as in 'in', $o p$ 'up' or $a f^{\prime}$ down'. These particles typically combine with a verbal stem to form a particle verb (also referred to as a phrasal, complex or separable verb). For example, in sentence (2), the verb val 'fall' and the particle af 'down' function together as the particle verb afval 'fall down'.

$$
\begin{aligned}
& \text { Hy gaan van die trap afval. } \\
& \text { he will from the stairs down-fall } \\
& \text { "He will fall down the stairs." }
\end{aligned}
$$

This is an example of a transparent particle verb construction where the meaning of the word is determined compositionally from the meaning of its two parts. Other features of transparent particle verbs include the fact that the particle can be replaced (e.g. oor-, af-, uitspring 'jump over/down/out') and that particles can be used contrastively (e.g. afspring 'jump down' vs. opspring 'jump up') (Wurmbrand 2000) ${ }^{3}$.

\subsubsection{Underlying syntactic structure of particle verbs}

The particle verb in sentence (2) is in its inseparable non-finite form, which refers to the fact that the verb does not carry information about tense. When in this form, only the past participle marker ge- (as in afgeval 'fell down') and infinitival te 'to' ((om) af te val 'to fall down') can occur between the particle and the verb root. However, the relative order of the particle and the verb root can change in certain syntactic contexts. In verb second structures found in Afrikaans as well as other West-Germanic languages, the finite component of the predicate (the verb root) is separated from the non-finite part (the particle), causing the particle to be stranded (Behrens 1998). In other words, the verb appears after the grammatical 
subject (hence "verb second"), resulting in a surface SVO order. This can be seen in sentence (3):

Hy val van die trap af. he falls from the stairs down

"He falls down the stairs."

Particle verbs are generally considered to have an underlying "small clause" structure in which there is a head-complement relation between the verb and the particle; for further information, readers are referred to more comprehensive texts (e.g. Den Dikken 1992; McIntyre 2007; Ramchand and Svenonius 2002; Wurmbrand 2000). This head-complement relation makes it possible, in satellite-framed languages, to describe Path (i.e. direction) within a single clause, along with prepositional phrases (PPs) which add further specification (Berman and Slobin 1994). PPs could add semantic information about either goal, path or source of movement, amongst others, depending on the specific preposition used (SaintDizier 2006). The goal relation refers to the end-point of a motion event encoded in the verb and is expressed by prepositions such as $n a$ 'to' and by 'at' (e.g. walk to the shop and stop at the shop). Source, in contrast, refers to the starting point of a motion event and is expressed by prepositions such as van 'from' (e.g. walk from the shop). The term "path" (written with lowercase p) refers to the route followed by a moving entity - essentially a continuum of locations - and is typically expressed by prepositions such as langs 'next to', verby 'past' and oor 'over', as in the sentence He drove past the shop (Biberauer and Folli 2004). Although path prepositions imply movement, they do not explicitly express the direction of movement. This term should not be confused with the umbrella term "Path" (written with uppercase P) used by Talmy (2000) and others to refer to the semantics of direction, path, goal and source of movement. Although Talmy's term is useful in capturing crosslinguistic tendencies and will still be used in that context, the additional terms "direction", "path", "location", "goal" and "source" will be used where more fine-grained distinctions are necessary.

A PP+particle construction thus enables the expression of information about direction, as well as source or goal of movement and is considered by Talmy (2000) to be the full expression of Path. This is illustrated in sentence (3), where information about direction ( $a f$ 'down') as well as information about source ( $v a n$ 'from') is expressed in a single clause by combining the particle verb afval 'fall down' with the simple PP van die trap 'from the stairs'.

\subsection{The development of spatial language}

Although children's descriptions of motion events resemble those of adults in their own language group from very early on (Choi and Bowermann 1991), there is increasing evidence for subtle differences as well. We will now consider the main findings relating to the development of particle verbs by children with and without language impairment in a range of languages. No such developmental data could be sourced for Afrikaans.

\subsubsection{Acquisition of particle verbs by typically developing children}

Isolated Path particles are acquired relatively early in child language development, emerging at around 14 to 16 months. Particles have been reported by many to be among the first singleword utterances of children acquiring English, German and Scandinavian languages (e.g. Bloom 1976; Bowermann and Choi 2001; Bowermann 1996; Nelson 1974; Kauschke and Hofmeister 2002; Strömqvist, Ragnarsdóttir and Richthoff 2001). At first, these particles are 
used like verbs, to request or comment on an activity; they are only later used to indicate the spatial relationship between objects or activities (Tomasello 1987).

Separable particle verbs emerge around two years of age and become more frequent and productive by the time children start to mark finiteness and grammatical relations (Behrens 1998). Behrens found that, although separable verbs were not among children's first verbs, they accounted for a respectable portion of 15- to 18-month-old children's verbal lexicon in German, Dutch and English. Behrens reported great productivity in the early use of verb particles: German children, for example, used $50 \%$ of the verb stems in their verb lexicon together with a particle. Semantically "light" verbs like make, do and go proved to be especially productive; for instance, the light motion verb go (Dutch gaan; German gehen) was used together with the spatial particles in, out and up in all three these languages, and with the adverbial particle auf 'on / up' in German. To conclude, spatial particles emerge early, are followed soon after by particle verbs and used productively from early on.

\subsubsection{Learning to talk about Path of motion}

A number of crosslinguistic studies seem to point to distinct developmental patterns in children's ability to use spatial language appropriately. We will focus on the developmental patterns described for the satellite-framed languages English and German.

As particles are acquired relatively early by German- and English-speaking children, it is not surprising that they are also among the first words used to express movement in narrative speech. Berman and Slobin (1994) reported that 3- and 4-year-olds acquiring English already use a wide variety of directional particles (e.g. down, in, out, off, on) together with some motion verbs and light motion verbs such as go, to express movement (e.g. get past, go away, put on, pick up). Initially, such direction-only responses predominate although they seem to be more frequent with some events (such as downward motion or departure) than with others (such as crossing events or upward motion) (Hickmann 2006). Similarly, Bamberg (1994:238) reported that 3-year-old German-speaking children already use a wider variety of directional particles to indicate Path "in a general way" (presumably specifying only direction). These Path-only responses typically consist of a light verb such as gehen 'go' and a particle (Ochsenbauer and Hickmann, in press).

Path-only responses decrease with age as the verb lexicon expands and children start using a greater variety of lexically more specified motion verbs (e.g. crawl, jump, slide) and PPs to express more specific information about Manner as well as path, goal and source of motion (Bamberg 1994; Hickmann 2006; Hickmann, Taranne and Bonner 2009). By the age of five, English-speaking children first start specifying the source of movement in addition to direction, e.g. The frog got out of his bowl (Berman and Slobin 1994). For example, in the sentence Some bees came out of the tree, the direction (out) as well as the source of movement (out of the tree) is expressed by the stringing together of a particle and a PP into a "doubly elaborated" locative trajectory (Berman and Slobin 1994). Young English-speaking children rarely use these structures, although they do not seem to have problems with the syntax (i.e. they do not make word order or particle placement errors when using these constructions). It could be that this type of structure is cognitively more demanding for young children since it requires them to express two types of information within the same conceptual frame, and that they seldom use it for this reason. Previous studies have found that children often focus on only one piece of information at a time, e.g. expressing only Manner or Path, 
in contrast to adults who generally express both (Hickmann 2006; Hickmann, Taranne and Bonnet 2009; Ochsenbauer and Hickmann, 2010, in press). Talmy (2000) considered Path, in addition to Motion, to be a defining feature of a motion event. Indeed, it seems that when young children of different languages focus on only one piece of information, it is most often Path rather than Manner (e.g. Ochsenbauer and Hickmann, in press). In a narrative context, information about Path is particularly relevant, since location changes of a protagonist have important implications for the overall discourse representation (Hickmann 2006). It is possible that this also applies to the verb+particle+PP structure in English: When faced with a choice between expressing information about direction and path/goal/source in a single clause, children choose the one that is most relevant in the discourse context. The remaining piece of information might still be expressed in a subsequent clause by so-called "clause stacking" (Berman and Slobin 1994), e.g. The boy fell off. He is in the water. Berman and Slobin (1994) also noted that younger children sometimes tend to overuse the type of linking structure formed by stringing together a particle and a PP, for example by adding a redundant of in sentences such as He knocked them off of the cliff or They're coming off of the tree. A possible reason for this finding is that children who are acquiring their first language may find it hard to determine when multiple aspects of a situation are linguistically realized and when they are not. This may also be related to specific properties of different verbs. In conclusion, it seems that young children might have difficulty in expressing the path/source/goal and direction of a motion event in the same conceptual frame, since this type of structure is both formally and semantically richer than structures in which only one piece of information is expressed.

Based on these findings, we can expect that the syntax of PP+particle structures is unlikely to be problematic for 6-year-old Afrikaans-speaking children. However, on a semantic and pragmatic level, the structures might be challenging for children to produce, as they require of children to package more than one piece of spatial information into a single clause. Afrikaansspeaking children could therefore be expected to perform somewhat differently than adults in their production of these constructions, possibly omitting one piece of information (most likely information about source/goal) in favour of the other (direction).

\subsubsection{Acquisition of particle verbs by children with language impairment}

Relatively few studies have examined the acquisition of particle verbs by children with language impairment, Watkins and Rice (1991) being a notable exception. They compared the verb particle and preposition use of three groups of preschool children aged 4 years 5 months to 5 years 7 months: (i) children diagnosed with specific language impairment, (ii) typically developing children matched on chronological age, and (ii) language-matched younger children. Preschoolers with language impairment performed significantly worse than their language- and age-matched peers in their production of verb particles, with the most common error being omission of particles (e.g. kick the bucket instead of kick the bucket over). There are many possible reasons why particle verb structures might be more difficult for a child with language impairment to acquire. One reason would pertain to the fact that particles combine with verb stems and occur in less predictable syntactic contexts than prepositions, making it harder for the child to extract consistent patterns from the input about the syntactic environment in which they are used. Although errors are expected to occur in a group of children with language impairment, it remains to be shown whether these errors resemble - or differ from - those made by typically developing children. 


\subsection{Research aims and hypotheses}

The main aim of this paper is to determine whether 6-year-old Afrikaans-speaking children use PP+particle verb structures in the same way that adults do. A second, related aim is to find out how children with language impairment use these structures, i.e. whether they make atypical errors when compared to typically developing children of the same age. These aims can be formulated as the following two hypotheses:

Hypothesis 1: In their production of $\mathrm{PP}+$ particle structures, typically developing 6-year-old Afrikaans-speaking children will make certain developmental errors not found in the adult group.

Hypothesis 2: Afrikaans-speaking children with language impairment will have more difficulty in producing PP+verb particle structures than their typically developing peers, and will make errors not found in the typically developing age-matched group.

\section{Method}

Data were obtained as part of a larger study on dialectal variation and developmental patterns in the production of prepositions and particle verbs in Afrikaans (cf. Oosthuizen 2009). Materials in the original study were divided into two contexts: (i) prepositions and (ii) $\mathrm{PP}+$ particle verbs. For the purposes of the current investigation, we will only discuss data relating to (ii), effectively half of the data from the original study. Note that the transcription, scoring and coding procedures relate to both contexts and will be reported accordingly. A toy elicitation procedure in which the examiner acted out directional motion events by means of toys and everyday objects, was used to elicit target $\mathrm{PP}+$ particle structures from participants.

\subsection{Participants}

There were three main participant groups: The first group consisted of 30 typically developing 6-year-old children, 15 speakers of Mainstream Afrikaans (MA) and 15 speakers of Kaaps, or Cape Afrikaans (CA). This group will be referred to as the TD group. The second group comprised 10 adults (five from each dialect) and will be referred to as the adult group. The third (LI) group consisted of three 6-year-old children diagnosed with language impairment. Participant characteristics are summarized in Table 1. Age and gender distribution for the first two groups was very similar across the two dialects.

Table 1. Participant characteristics

\begin{tabular}{llrlcrr}
\hline Dialect & Age & Group Number & Mean age & $\begin{array}{c}\text { Age range } \\
\text { (years.months) }\end{array}$ & Female & Male \\
\hline Mainstream & Adults & 5 & 29.8 & $24-39$ & 3 & 2 \\
Afrikaans & Children & 15 & 6.3 & $6.0-6.11$ & 7 & 8 \\
& LI & 3 & 6.5 & $6.0-6.9$ & - & 3 \\
Cape & Adults & 5 & 28.6 & $24-38$ & 3 & 2 \\
Afrikaans & Children & 15 & 6.2 & $6.0-6.8$ & 8 & 7 \\
\hline
\end{tabular}

MA speakers were recruited from Paarl and the northern suburbs of Cape Town, and CA speakers were recruited from the Ruyterwacht, Heideveld and Elsiesriver suburbs on the Cape Flats. CA participants were from working class and lower middle-class backgrounds whereas MA participants were mainly from middle- to upper-middle class backgrounds. These socio- 
economic differences were expected, seeing that CA is mostly viewed as a working class dialect (cf. Stone 1995). The first language of all participants was Afrikaans. Note that, since the focus of this paper is on developmental, not dialectal differences, participants' dialect status will only be mentioned in cases where it has an influence on the findings for $\mathrm{PP}+$ particle verb structures. For a more thorough discussion of the findings on dialectal differences, see Oosthuizen (2009).

Adult participants provided biographical information by completing a questionnaire, and gave informed consent for participation prior to testing. Parents provided background information on the child participants by completing case history forms, and gave informed consent for participation. Informed assent was also obtained from each child participant individually.

All participants in the TD group were either in preschool or in their first school year at the time of testing and were typically developing according to their parents and teachers. All child participants passed a puretone hearing screening test.

The LI group consisted of three MA-speaking males recruited from the northern suburbs of Cape Town. Two of these children were diagnosed as language-impaired by a speechlanguage therapist and were receiving therapy at the time of testing. The third child was referred by his preschool teacher who was concerned about his language development and reported that he made frequent word order and other syntactic errors. Results of a standardised test of receptive language abilities conducted by the first author revealed a significant delay in receptive language skills, and spontaneous language data indicated several syntactic errors. For financial reasons, this child was not receiving therapy at the time of data collection. He was judged by his teacher and parents to be typically developing in all other respects. On the basis of these findings, he was diagnosed with LI and included in the study. There were also no observable causes for the language difficulties of the other two LI participants, i.e. there was no evidence of hearing loss, neurological pathology or cognitive or socio-emotional difficulties. Children with this type of language disorder often remain undiagnosed. This is especially the case in more disadvantaged communities that have limited access to clinical services, hence the limited number of LI participants.

\subsection{Materials}

The spatial particles in 'in', uit 'out', af 'down' and op 'on' were selected as target particles as they are productively used by young children and adults, often occur in different particle verbs and play an important role in the expression of motion events in Afrikaans. Note that these particles can also function as lexical prepositions in (mainstream) Afrikaans, with the exception of the adverb af 'down'. The two different verbs used with each target structure are given in Table 2. These verbs were selected because they often occur with the target particles in particle verb constructions and represent common everyday actions that can be easily acted out with toys. Contexts in which $\mathrm{PP}+$ particle constructions containing the target particles and verbs could plausibly occur, were identified and formulated as target sentences (e.g. Die kat $\mathrm{klim}$ by/teen/met die trap op 'The cat climbs at/against/with the stairs up = The cat climbs up the stairs'). As can be seen from this example, in MA different prepositions can often be used together with the target particle, resulting in essentially the same meaning. The grammaticality of these sentences was checked by first language speakers of Afrikaans. Directional verbs (as discussed in Section 1.1.1) were not included in the materials, as these verbs would not reliably elicit a directional particle, and the aim was to create a context in 
which particle production would be more or less obligatory. For example, the verb spring 'jump' in Afrikaans already incorporates information about some degree of upward motion and therefore use of the directional particles op 'up', uit 'out' and in 'in' is optional. For this reason, the verb spring 'jump' was used only with the particle af 'down' and not with the particles op, uit and in. $\mathrm{PP}+$ particle structures were elicited in present tense, i.e. with the verb in second position in the main clause (as illustrated in sentence (3)).

Table 2. Verbs used with target items

\begin{tabular}{|l|l|l|l|l|}
\hline Target & AF 'down' & IN 'in' & UIT 'out' & OP 'up' \\
\multirow{3}{*}{ Verb } & spring & loop & loop & klim \\
& 'jump' & 'walk' & 'walk' & 'climb' \\
\cline { 2 - 3 } & val & $r y$ & ry & ry \\
& 'fall' & 'drive' & 'drive' & 'drive' \\
\hline
\end{tabular}

\subsection{Procedure}

Each participant had four opportunities to produce a particular target item, that is, a structure containing a PP and target particle. This made allowance for non-targeted types of responses and increased the possibility of obtaining at least one desired response per target item. Target items were elicited by means of age-appropriate toys - a Toymobil play house with stairs and furniture, a toy dog, cat, boy etc. - and actual objects, such as an apple, jacket, shoe and dishcloth. The first author used these toys and objects to act out various situations which involved directional motion of an entity (e.g. a car driving into the house). In the case of the particle in 'in', for example, the experimenter acted out two situations in which an entity was driving into something, and two in which an entity was walking into something. The participant was then asked to describe what was happening. Two control items were included to control for the possible effect of syntactic priming, a phenomenon where speakers are more likely to produce a sentence of a particular form if they have had recent prior experience with that form (Huttenlocher, Vasilyeva and Shimpi 2004). Control items were transitive particle verbs with the particles af 'off' and uit 'out' (e.g. afvee 'wipe off = wipe clean', uitsteek 'stick out') that express non-spatial meaning. Although these two particles are phonologically identical to the target particles, they require an obligatory DP argument, in contrast to the target particle verbs which take an (optional) PP as an adjunct. As with the target items, participants had four opportunities to produce each control item. The resulting 24 sentences were pseudorandomized and divided up over two lists.

As different types of linguistic items were included in the experiment (e.g. intransitive versus transitive particle verbs), different question prompts were used to elicit the desired responses. The target PP+particle structures were elicited as follows: first, the first author asked the open-ended question What is happening now?. Based on the participant's response, the author proceeded to the next level of prompting. If the participant gave no response or another related response after the first prompt, the author asked a more focused question, e.g. What is the boy doing?. If in answer to the more focused question, the participant produced the particle verb but no prepositional phrase (which is an adjunct, and therefore optional) or produced a particle but with an untargeted verb, the author asked a where-question (this time providing the target verb and particle) followed immediately by sentence completion prompt (e.g. Where does the boy fall off? He falls ...). This third prompt was also used if, after the second prompt, the participants produced only a particle verb. This prompting hierarchy was successful in eliciting target responses in most cases. 


\subsection{Transcription}

The responses were transcribed and scored by the first author. To evaluate the reliability of this transcription and scoring, five samples were randomly selected and independently analyzed by the third author: Two samples each were taken from the adult and TD group (one from a speaker of each dialect) and one from the LI group. An interrater reliability of 99,2\% and $96,9 \%$ was found for the transcription and scoring, respectively.

\subsection{Coding}

A distinction was made between pragmatically and grammatically correct utterances in either the mainstream dialect (MA correct; hereafter referred to as "MA responses") or the Cape Afrikaans dialect (CA correct; hereafter referred to as "CA responses"). Little is known about the production of $\mathrm{PP}+$ particle structures in Cape Afrikaans; this was one of the research gaps addressed by the original study (Oosthuizen 2009). Therefore, CA responses in this paper refer to the type of non-mainstream response researchers expected to find in the Cape Afrikaans dialect based on available literature.

Remaining responses were coded according to the way in which they differed from the expected MA and CA responses, and combined into the general category 'Other'. Almost all the responses in this category were characterised by omission of the directional particle. In other words, the participant produced a simple PP - in which the preposition was phonologically identical to the target particle - instead of a $\mathrm{PP}+$ particle structure (see Table 3 below). With regard to the child participants, the category also contained isolated instances of other responses in which there seemed to have been confusion between the goal and source of motion, and some in which incorrect prepositions were used with target particles. These types of responses did not occur in the adult group and represented only $1.4 \%$ of the total responses in the TD group and $8.3 \%$ in the LI group. For this reason, these responses will not be considered as a distinct response category. It will, however, be taken into account when comparing the performance of the LI and TD groups in Section 4.2. The original 'Other' category mentioned above will henceforth be referred to as Particle Omission (PO) responses. MA, CA and PO responses, summarised in Table 3, consequently represent the main types of responses found.

Table 3. Main response types

\begin{tabular}{|c|c|}
\hline \multirow{2}{*}{ MA response } & Preposition and particle are different lexical items. \\
\hline & $\begin{array}{l}\text { e.g. Hy klim by / teen die trap op } \\
\text { he climbs at / against the stairs up } \\
\text { "He climbs up the stairs." }\end{array}$ \\
\hline \multirow[t]{2}{*}{ CA response } & $\begin{array}{l}\text { Preposition and particle are phonologically and/or semantically the } \\
\text { same. }\end{array}$ \\
\hline & $\begin{array}{l}\text { e.g. Hy klim op die trap op } \\
\text { he climbs up the stairs up } \\
\text { "He climbs up the stairs." }\end{array}$ \\
\hline \multirow[t]{2}{*}{$\begin{array}{l}\text { Particle omission } \\
\text { (PO) response }\end{array}$} & $\begin{array}{l}\text { Preposition is phonologically identical to the target particle, but the } \\
\text { particle is omitted. }\end{array}$ \\
\hline & $\begin{array}{l}\text { e.g. Hy klim op die trap } \\
\text { he climbs up the stairs } \\
\text { "He climbs up the stairs." }\end{array}$ \\
\hline
\end{tabular}


Responses were excluded from the analysis if the participant (i) produced only the appropriate verb or particle verb (e.g. Hy val (af) 'he falls (down)') and the desired PP+particle verb structure could not be elicited by further prompting; (ii) produced a different, but pragmatically appropriate response, or (iii) gave no response. The responses in (i) to (iii) were treated as missing values, as they were likely a consequence of the experimental setup rather than a reflection of the participants' grammatical abilities.

\subsection{Analysis}

Four responses were obtained from each participant for a particular item. However, the 6year-olds showed considerable variation in the types of responses given, which meant that the four responses for each item were not always of the same type, complicating the analysis somewhat. The analysis will therefore be largely descriptive or qualitative in nature; this is also the case for the adult and LI groups, both of which consisted of a limited number of participants. In order to make judgements about statistically significant differences between typically developing participants from different dialects, a Generalized Estimates Equation (GEE) was conducted.

\section{Results}

The analysis will firstly focus on patterns of responses across the TD and adult groups to determine whether there were any differences between these two groups, differences which could be developmental in nature. Differences within the adult group due to dialect will then also be examined, as they might influence the between-group comparison. In cases where observable differences between the dialect groups were statistically significant, results of a GEE analysis will also be reported. Results of a verb analysis will also be reported and, lastly, a qualitative analysis of results from the LI group will be presented.

\subsection{Developmental patterns for $\mathbf{P P}+$ particle structures}

\subsubsection{Pattern of responses in the adult group}

The most important finding for the adult group was as follows: expected non-mainstream (CA) responses were only found for the particles in 'in' and uit 'uit', and not for af 'down' and op 'up'. The finding that the CA responses found were produced interchangeably with MA responses by adults from both dialects, suggests that this does not represent an instance of dialectal variation. Previous studies have noted that directional PPs in which the particles in and uit are semantically and phonologically identical to the preposition (e.g. loop in die huis in 'walk into the house') have gradually become more acceptable in MA and are used interchangeably with more mainstream structures (Donaldson 1993; Ponelis 1979; Biberauer and Folli 2004). Our findings show that this also seems to apply to PP+particle verb structures. Instead, the results point towards a different type of dialectal variation relating to the production of Particle Omission (PO) responses. The results will now be discussed separately for each target particle.

For the particle af 'down', MA responses were the most frequent regardless of dialect; it was also the only type of response made by MA speakers. No instances of the expected nonmainstream (CA) response were found for this particle. However, one participant in the CA group produced three PO responses (representing 15\% of the total responses in this group) in which he omitted the directional particle and used the adverb af 'down' as a preposition in a 
PP (i.e. Hy val af die trap 'He falls down the stairs'). This type of utterance differs in two important ways from MA: Firstly, the adverb af 'down' does not occur as a preposition in MA and, secondly, MA typically employs particles (or postpositions) to express directional meaning. In other words, this participant used a simple PP, typically associated in MA with locative events, to express a motion event. This utterance therefore seems to imply two instances of dialectal difference in the description of downward motion, although it is of a different type than previously expected and was not found for all the CA speakers.

For the particle in 'in', speakers of MA produced both MA and CA responses - the latter being far more frequent - but no PO responses. For speakers of CA, however, the distribution of responses was as follows: $\mathrm{MA}<\mathrm{CA}<\mathrm{PO}$. As can be seen from Figure 1, PO responses accounted for almost half of the responses in the CA group. In other words, CA-speaking adults showed a preference for structures such as Hy loop in die huis 'he walks in the house' to express directional meaning, where MA speakers would typically use the additional directional particle in 'in' (cf. Table 3).

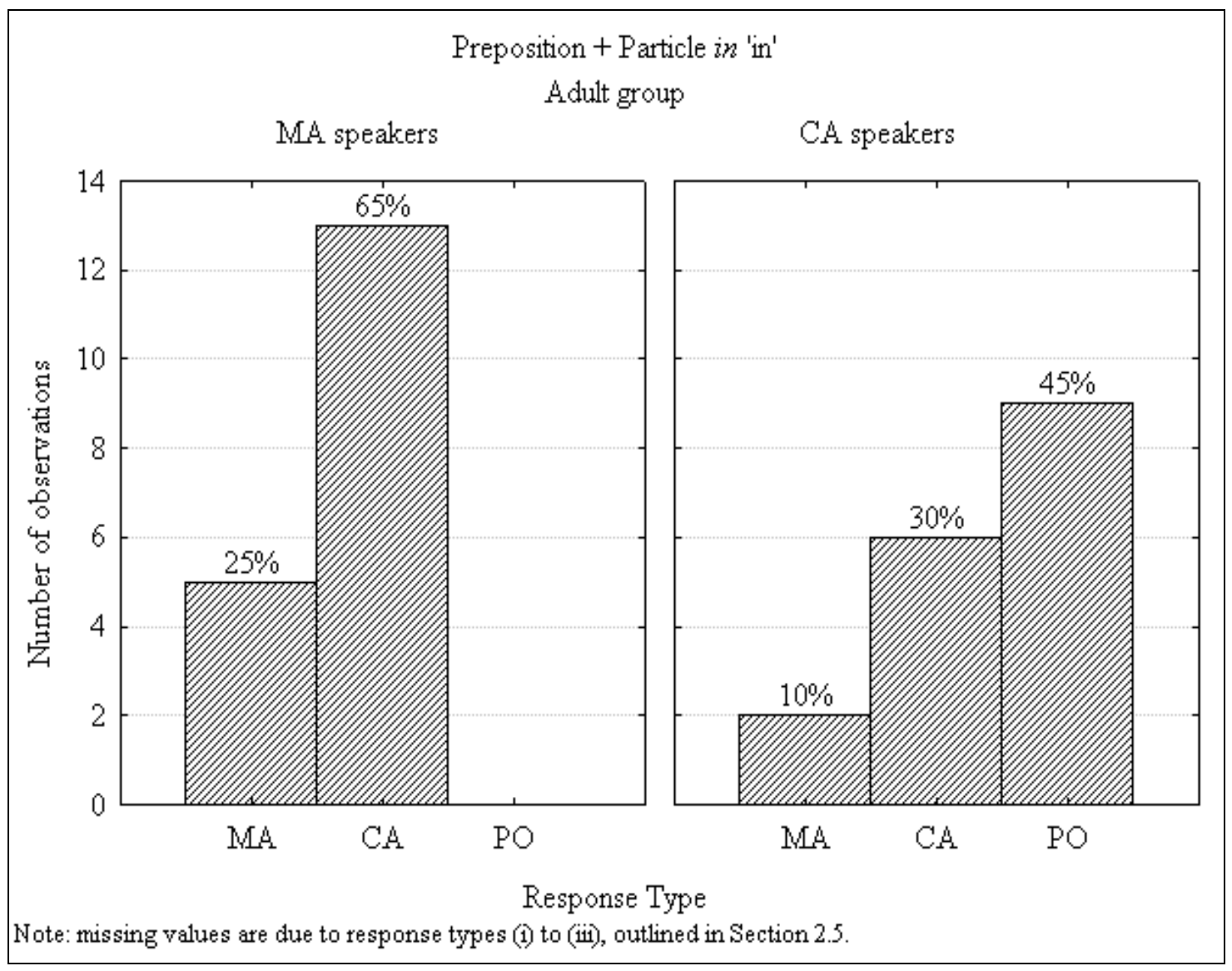

Figure 1. Responses of the adult group for the PP+particle in 'in'.

Regarding the particle uit 'out', speakers of MA showed the same pattern as with in 'in', producing both MA $(25 \%)$ and CA $(70 \%)$ responses but no PO responses. Speakers of CA performed similarly, showing a clear preference $(60 \%)$ for CA responses. One instance of particle omission was found in the CA group with the verb ry 'drive'. However, the particular 
sentence Die kar ry uit die garage 'The car drives out (of) the garage' is also considered acceptable (although less "standard") in MA. Apparently the verb ry 'drive', when used in the context of forward-directed motion, already encodes some degree of directional meaning, rendering a directional particle optional. Particle omission in the case of the particle uit 'out' is therefore not considered an instance of clear-cut dialectal variation.

Differences between the two dialect groups were particularly striking for the target particle $o p$ 'up'. As can be seen from Figure 2, adult MA speakers produced only MA responses, except for one instance of a PO response. CA speakers showed exactly the opposite pattern, producing mainly PO responses with only one instance of a MA response. No CA responses were found for this particle. In other words, for the particle op 'up', speakers of MA almost always produced the typical $\mathrm{PP}+$ particle structure to express source/path and direction of movement (e.g. ry by/met die trap op 'drive at/with the stairs up'), while speakers of CA almost always omitted the particle and produced only a PP in which the preposition is phonologically and semantically identical to the omitted particle (e.g. ry op die trap 'drive on the stairs').

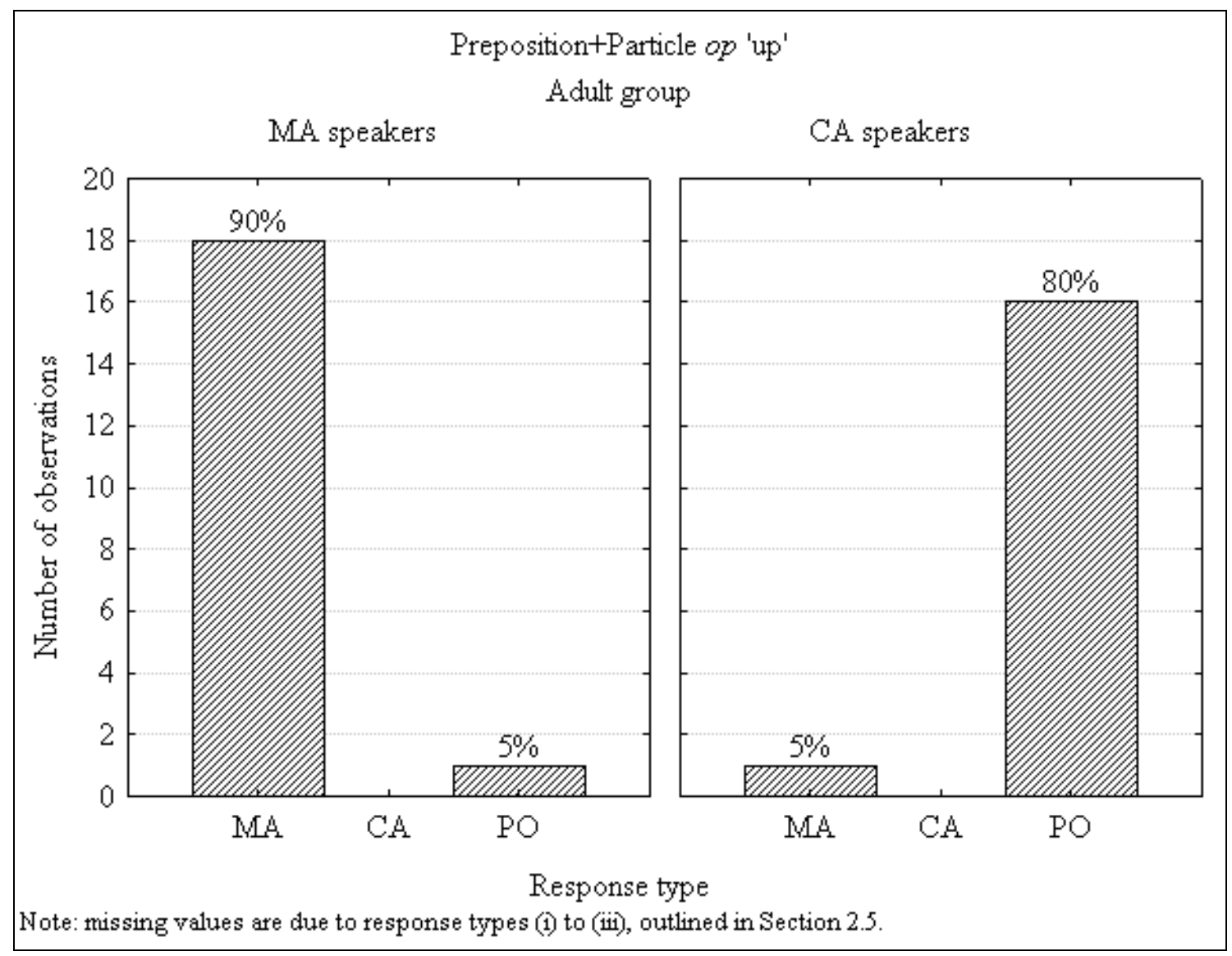

Figure 2. Responses of the adult group for the PP+particle op 'up'

\subsubsection{Pattern of responses in the TD group}

The most important findings for the TD group were as follows: Firstly, 6-year-olds showed considerable variation in the types of responses they produced. For instance, for the particle af 
'down', some participants produced two CA responses (e.g. spring af die trap af 'jump down the stairs down') and one or two MA responses (e.g. spring by/van die trap af 'jump from/at the stairs down') and/or PO responses (e.g. spring af die trap 'jump down the stairs'). This is in contrast to the adult group, who responded more consistently. Secondly, CA responses were produced by all children regardless of dialect. Recall from Section 3.1.1 that CA responses were only found in the adult group for the particles in 'in' and uit 'out'. Thirdly, PO responses where the directional particle was omitted were commonly produced by all 6-yearolds regardless of dialect. Differences between the adult and TD groups will be discussed in more detail in Section 4.1. The pattern of responses in the TD group will now be discussed for each particle separately.

Regarding the particle af 'down', MA responses predominated (62\% in MA, 57\% in CA), followed by PO responses (20\% in MA, 32\% in CA) and then CA responses (18\% in MA, $11 \%$ in CA). There were no significant differences between dialect groups for any of the response types. In PO responses, the adverb af 'down' was used as a preposition (e.g. val af die trap 'fall down the stairs'). As mentioned in Section 3.1.1, this type of response seems to be permitted in CA, but not in MA; however, it was produced by children from both dialects with more or less the same frequency. These findings are illustrated in Figure 3.

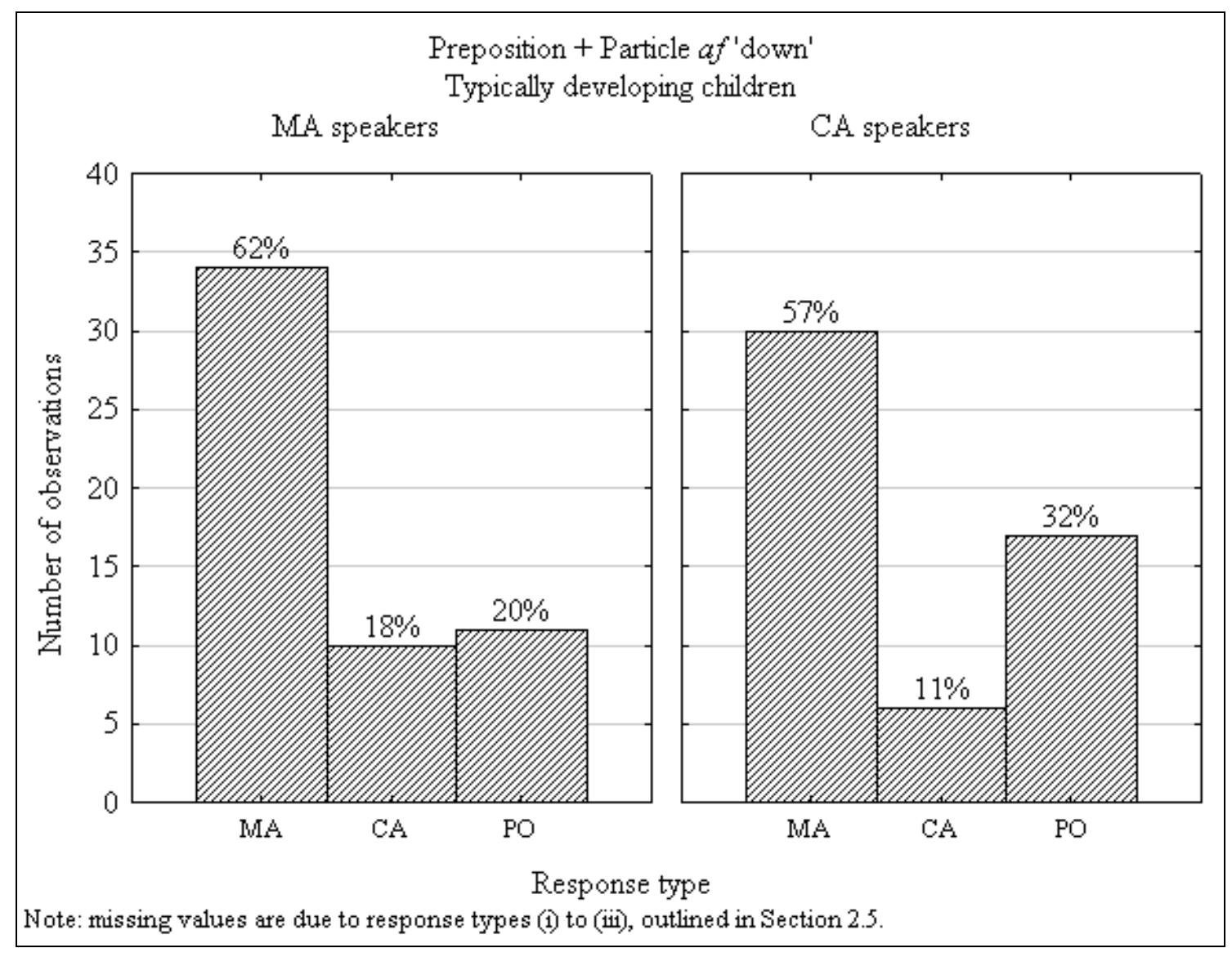

Figure 3. Responses of the TD group for the PP+particle af 'down' 
For the particle in 'in', PO responses in which the directional particle had been omitted (e.g. loop in die huis 'walk in the house') occurred most frequently in both dialects (54\% in MA, $73 \%$ in CA). This was followed by CA responses (37\% in MA; $21 \%$ in CA) and then MA responses (9\% in MA, 5\% in CA); again there was no significant difference between dialects. In other words, 6-year-olds showed a preference for simple PP structures such as Hy loop in die huis 'he walks in the house' to express directional meaning (cf. Table 1).

For the particle uit 'out', MA responses were least frequent in both dialects (14\% in MA, $11 \%$ in CA). Speakers of MA mostly gave CA responses (54\%), followed by PO responses (32\%), whereas speakers of CA gave slightly more PO responses $(48 \%)$ than CA responses $(41 \%)$. However, these trends in the data (which seem to suggest dialectal variance) do not approach statistical significance.

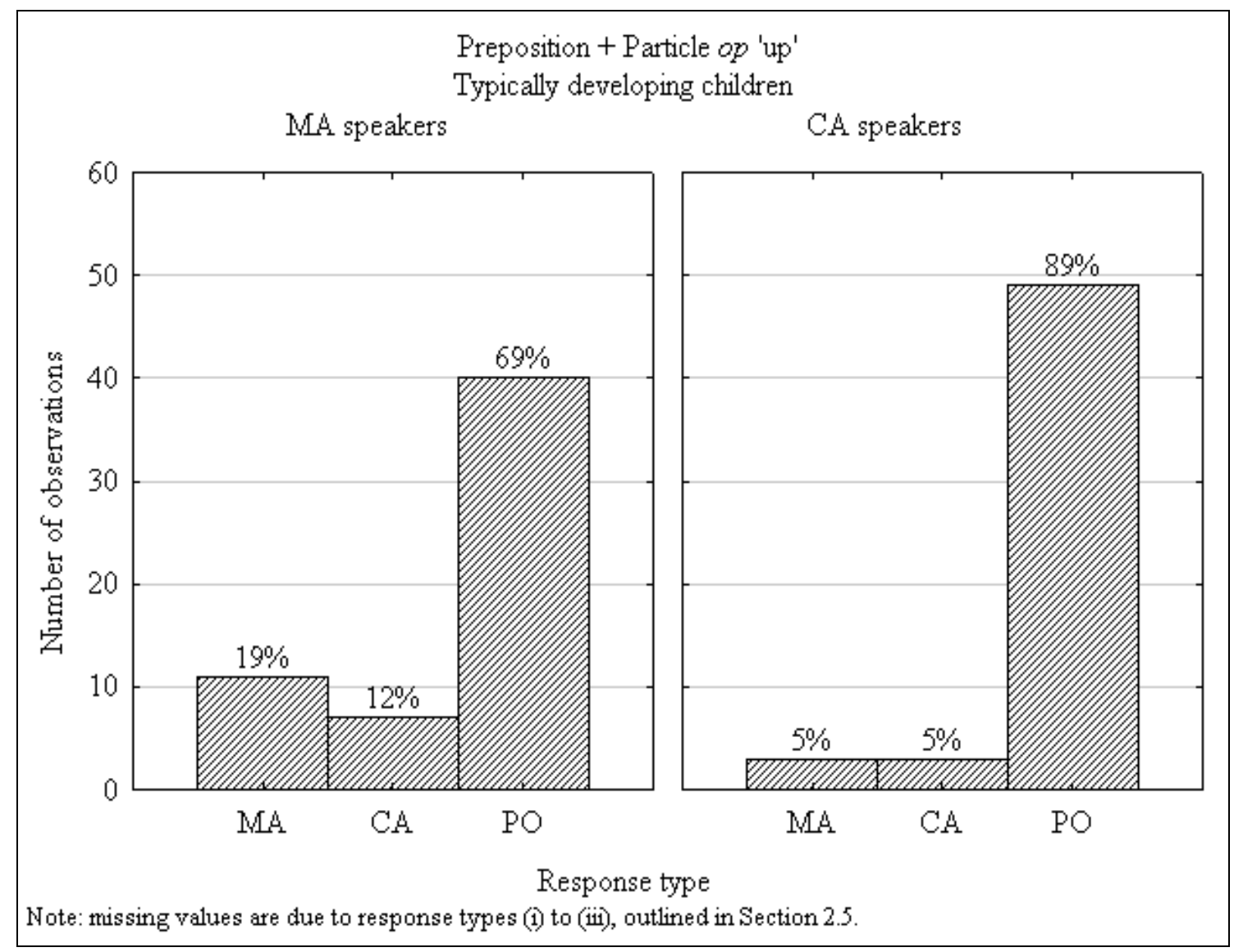

Figure 4. Responses of the TD group for the PP+particle op 'up'

Regarding the particle op 'up', PO responses accounted for most of the observations in both dialect groups (up to $89 \%$ for speakers of CA). As seen in Figure 4 above, only a few MA and CA responses were found for this particle. In other words, 6-year-olds from both dialects consistently preferred to produce PPs rather than $\mathrm{PP}+$ particle structures to express upward motion. 


\subsubsection{Verb analysis}

It is possible that particle omission responses in the TD group might have been due to specific verbs used in this experiment (recall that each target item was elicited by means of two different verbs). We examined this possibility by classifying response types in the TD group per verb and comparing the relative frequency of occurrence. Although slight variation was observed between verbs, the GEE analysis showed no significant difference for any of the items ( $\mathrm{p}>.05)$, which indicates that the verbs used in this experiment did not seem to be biased toward a certain response type. An analysis of the interaction between the factors group and verb also did not show a significant difference for any of the target items. This suggests that the choice of verb does not account for any of the observed differences between the two (TD) dialect groups, and vice versa; the observed differences between the dialect groups did not influence responses given with a particular verb.

\subsection{Children with language impairment}

PO responses represent the majority of responses found in the LI group for all particles (41 out of the total 48). In other words, the children with LI in the current study almost always omitted the directional particle in the target structures. The remaining responses found in this group included a single CA response for the particle op (klim op op die dak 'climb up up the roof') as well as three different types of semantically unusual responses made by one participant: two occurring with the particle af 'down' and one with the particle uit 'out'. In the first, he produced a $\mathrm{PP}+$ particle structure with the target particle af but an inappropriate preposition (op 'on'), e.g. Hy spring op die dak af 'He jumps on the roof down' and Hy val af op die trappe 'He falls down on the stairs'. When used in this way, the preposition op 'on' seems to indicate the goal or end-point of motion, i.e. that the boy is falling down onto the stairs. This was not appropriate in the specific experimental context, where the boy was standing on the stairs and then fell down onto the ground; in this context, the stairs were the source (i.e. starting point) of motion. In another, very similar response (Dit val af en op die dak 'It falls down and on the roof') he inserted en 'and' before the PP. As in the previous example, use of the preposition $o p$ and insertion of en result in the roof being interpreted as the goal instead of the source of motion, the latter being the correct interpretation in the context, where the bucket stood on the roof and then fell down onto the ground. The second unusual type of response - found for the particle uit 'out', namely Hy loop uit in die huis uit 'he walks out in the house out' - consisted of the particle verb uitloop 'walk out' as well as two preposition-like elements. Use of the preposition in 'in' is semantically inappropriate in this context. The third unusual type of response, also for the particle uit 'out', was very similar to the second since it involved incorrect substitution of a preposition (e.g. ry uit in die garage 'drive out in the garage'). However, in this type of response the participant produced structures containing only one particle and preposition. See Section 4.2 for further discussion of these response types.

\section{Discussion}

The main aim of this paper was to determine whether young Afrikaans-speaking children use $\mathrm{PP}+$ particle verb structures with the spatial particles af 'down', in 'in', uit 'out' and op 'up' in the same way as adults do. In order to achieve this aim, the performance of 6-year-old children was compared to that of adult participants from the same language community. A second, related aim was to determine how children with language impairment produce these types of structures. The findings relating to these aims will now be discussed in more detail. 


\subsection{Differences between the adult and TD groups}

Results for the adult group indicate that (i) adults responded consistently and (ii) PO responses were found only in the CA group and were most pronounced for the particle op 'up'. In contrast, results for the TD group indicate that (i) 6-year-old participants showed considerable inconsistency in their responses, (ii) PO responses were found for all particles and were produced by all children in the TD group, regardless of their dialect status, and (iii) CA responses, which did not occur in the adult group, were found in the TD group for all target items. CA responses even seemed to be used slightly more by 6-year-old MA speakers than by 6-year-old CA speakers (although this difference between dialect groups was not statistically significant). MA responses were the least frequent for all target items except for the particle af 'down'. In other words, the expected non-mainstream response was produced by all children regardless of dialect, with more or less the same frequency.

On the basis of these main findings we can conclude that there are two main differences between the adult and 6-year-old participants: firstly, 6-year-olds from both dialects produced some CA responses with the particles $a f^{\prime}$ 'down' and op 'up'; in contrast, no CA responses were found with these same particles in the adult group. Secondly, only CA-speaking adults produced PO responses (most notably for the particle op 'up') whereas, in the TD group, children from both dialect groups produced PO responses. Taken together, these findings suggest that developmental, rather than dialectal, factors are responsible for this difference between the adult and TD groups. This provides support for hypothesis 1, which predicted that typically developing 6-year-olds, in their production of PP+particle structures, will make certain developmental errors not found in the adult group; developmental errors here refer to the frequent use of CA and PO responses by typically developing children from both dialects. Possible explanations for these findings will now be discussed separately.

\subsubsection{Dialectal factors influencing response options}

The data from the adults suggest that in non-mainstream varieties of Afrikaans, there seem to be two possible manners in which to express directional meaning: either (i) syntactic doubling of a directional element (e.g. Hy val af van die trap af 'He falls down from the stairs down = He falls down the stairs') $)^{4}$ or (ii) omission of the directional element (e.g. Hy val af die trap). This last type of structure is considered more "non-standard" than the first, which also occurs in MA. Although the structure in (ii) was produced by CA-speaking adults as well as 6-yearolds of either dialect, the underlying reasons for the occurrence of this structure differ between the groups. Developmental factors are implicated in the case of the 6-year-old participants, as this response type was used by the majority of children, regardless of dialect. However, dialectal factors are implicated in the case of adult participants - omission of a directional particle is evidently allowed in $\mathrm{CA}$ in cases where the preposition and particle are phonologically the same and express the same semantic information. Children growing up in CA-speaking communities will likely retain the PO response discussed here as a possible alternative for expressing directional meaning. However, PO responses are likely to disappear gradually from MA-speaking children's speech, as such a structure is not allowed in MA (except in cases where the verb already encodes information about rapid directional movement). This was indeed the case for the MA-speaking participants in the adult group, who showed a preference for either MA responses (for particles $a f$ and $o p$ ) or CA responses (for particles in and uit). In other words, the mainstream dialect allows one of two possible response types whereas there seems to be a choice in CA between two or even three different response types. For both dialects, the choice seems to depend on the lexical item concerned. 
The results also indicated some variation within the group of particles regarding the frequency of response types, e.g. some particles elicited more CA or MA responses than others. This variation is likely due to specific lexical properties of individual particles.

\subsubsection{Developmental pattern for $\mathbf{P P}+$ particle structures 4.1.2.1 Verb particle omission by typically developing children}

It is unlikely that 6-year-olds omitted directional particles due to incomplete mastery of the syntactic structure of particle verbs or PPs. As seen in the literature review, isolated particles emerge relatively early in child language and are used productively (and correctly) from a very young age. Also, prepositions used in a spatial sense (e.g. in 'in', uit 'out', op 'on', by 'at') are acquired relatively early (cf. Clark 1973; Grimm 1975; Tomasello 1987; Vorster 1984 in Tomasello 1987). The intransitive particle verbs used as control items in the current study (e.g. trek jou skoen uit 'take off your shoe') were also used correctly by almost all the participants. Instead, the main difficulty for the children in this study seems to lie in using spatial verb particles together with an additional PP, where such a PP expresses information about goal, source or path of motion.

According to Berman and Slobin (1994:161) this type of "doubly-elaborated locative structure" represents the main structural advance in the expression of motion events, as it allows expression of two types of information (direction and path/goal/source) in the same clause. This structure is both formally and semantically richer than those in which only one type of information is expressed and could therefore be more cognitively demanding for the child. Previous studies have found that young children seldom use these types of structures in their spontaneous language, suggesting a general difficulty in expressing both information about source/goal/path and direction of a motion event in the same conceptual frame (Berman and Slobin 1994). This seems to be a likely explanation for findings of this study as well. Although no studies explicitly examining the development of PP+particle verb structures in Germanic languages could be traced, several crosslinguistic studies have shown that young children speaking typologically different languages tend to focus on only one type of information at a time when expressing motion events (e.g. Hickmann 2006; Laloi 2007; Ochsenbauer and Hickmann 2010, in press). This is generally information about Path or, more specifically, about direction (as expressed by means of a verb particle). In discourse contexts, information about the direction of movement of a protagonist is arguably more important than information about the source or goal of that movement (Hickmann 2006).

In the current investigation, however, children omitted the directional particle, which seems to contrast with findings reported for other languages. In other words, information about direction was omitted while information about path, goal and source was expressed. A possible explanation for this finding is that children are exposed to ambiguous input with regard to these structures. Recall from Section 1.1.1 that "locative" PP structures expressing directional motion do occur in Afrikaans, in cases where the verb already encodes a certain degree of rapid directional information (e.g. spring in die water 'jump in/into the water'). In other words, children are exposed to language input in which directional motion is sometimes expressed by simple PPs and sometimes by more complex PP+particle verb structures. This could lead children to conclude that either of these options is available for expressing directional meaning in Afrikaans. If faced with a choice, they are likely to choose the simpler (PP) structure over the more complex ( $\mathrm{PP}+$ particle) one when expressing directional motion. 
It is possible that this was the strategy followed by the 6-year-olds in this study when faced with the cognitively demanding task of expressing two types of information in the same clause.

\subsubsection{CA responses in the TD group}

CA responses were produced with all target particles by children from both dialects. In other words, PP+particle structures in which the preposition and particle are phonologically and semantically the same (e.g. klim op die dak op 'climb up the roof (up)'; val af die trap af 'fall down the stairs (down)') were one of the response options available to 6-year-olds. Adults from both dialects only produced these types of responses with the particles in 'in' and uit 'out'. This suggests that CA responses, as found in the TD group, might represent an intermediate developmental milestone in the acquisition of PP+particle structures. It is closer in form to the "standard" MA response than to the PO responses; structurally speaking, PO responses differ the most from the standard, and can be considered to be the least sophisticated response of the three. Berman and Slobin (1994) reported a type of response used by English-speaking children that seems very similar to CA responses in Afrikaans. They noted that young children, rather than avoiding challenging verb+particle+PP structures, instead seemed to overuse them - for example, by adding a redundant preposition of in the sentence He knocked them off of the cliff. In this context, the preposition and the particle are phonologically very similar, as is the case in the CA responses in Afrikaans. One possible explanation for this finding is that young children find it hard to determine when multiple aspects of a situation are linguistically realized and when they are not, causing them to sometimes make overgeneralisation errors. This may also be related to specific properties of different verbs. This type of error might be typical of young children acquiring WestGermanic languages, although more information on other languages such as German and Dutch is needed to confirm this hypothesis.

\subsection{Children with language impairment}

Children with LI produced mainly PO responses. In other words, with the exception of one instance of a CA response for the particle $o p$ 'up', no CA or MA responses were found for any of the particles. This finding contrasts with results for the TD group who produced both CA and MA responses, showing considerable variation with regard to response type. The fact that mainly PO responses (arguably the least sophisticated response type produced by the 6-yearolds) were found for the particles $a f$ 'down', in 'in', uit 'out' and $o p$ 'up' suggests that children with LI show an expressive delay when compared to their typically developing peers.

One participant in the LI group also produced a few unusual types of responses with the particles af 'down' and uit 'out'. These responses were of three types: The first type seemed to indicate confusion in the correct expression of goal and source of motion (e.g. jump af van die grond 'jump down from the ground'). In another, similar response (Dit val af en op die dak 'It falls down and on the roof') en 'and' was inserted before the PP. As in the previous example, use of the preposition $o p$ and insertion of $e n$ result in the roof being interpreted as the goal instead of the source of motion. This type of response was also produced by one MAspeaking and two CA-speaking 6-year-olds for the same particles, which suggests that it represents a normal (although less common) developmental error.

The second type of unusual response produced by this particular participant with LI, seemed to indicate incorrect substitution of a preposition in a structure containing three 
particle/preposition elements. The particular utterance Hy loop uit in die huis uit 'He walks out in the house out' produced by this participant, appears very similar to ones commonly found in colloquial Afrikaans (e.g. hy loop uit by die huis uit 'he walks out at the house out = he walks out of the house'), although the use of in 'in' is semantically inappropriate in this particular context. Note that, since two of the elements in this first type of utterance (containing three particle/preposition elements) are phonologically identical, it is unclear whether they are particles or postpositions. We can conclude that in 'in' is a preposition in this utterance, as it is the case-assigning head of the PP in die huis 'in the house'. There are two possibilities, then: The first is that the first uit is a particle, occurring in front of the PP, and the second uit is a postposition, forming part of the (semantically incorrect) circumpositional phrase in die huis uit 'in the house out'. The second possibility is that the second uit is a copy of the first uit, the result of syntactic doubling of the kind often found in colloquial MA. The possibility that an extra preposition in was erroneously 'inserted' after the preposition uit, in the circumpositional phrase uit die huis uit 'out the house out', is unlikely, as structures containing three spatial elements commonly occur in MA.

The third unusual response type made by this participant was similar to the second since it also involved incorrect substitution of a preposition (e.g. ry uit in die garage 'drive out in the garage'). However, whereas the second type contained three particle/preposition elements, the third contained only one particle and a preposition. This third type of response was also produced by one participant in the TD group (for the particle af 'down'), suggesting once again that it represents a normal (although less common) developmental error. However, the second type of response was only found in the LI group, which suggests that it might represent an atypical error. This therefore provides partial support for hypothesis 2, which predicted that children with LI will have more difficulty in producing PP+verb particle structures than their typically developing peers, and will make errors not found in the TD group. However, due to the limited size of the LI group, the generalizability of these findings is limited and further research is needed to support this hypothesis.

A better understanding of normal dialectal variation is important in acquisition research. In order to decide what is typical and atypical in child language, researchers need to recognise and distinguish between differences in language performance that are either due to dialect or development (Seymour 2004). As illustrated by this study, it is only once these normal sources of language variation have been acknowledged that instances of language disorder can be accurately and fairly identified.

\section{Conclusion}

The study contributed to the limited knowledge base on normal language development in Afrikaans-speaking children, specifically regarding spatial language, as well as to the equally limited knowledge base on the characteristics of language impairment in Afrikaans. The relatively small number of participants in the adult and LI groups could, however, have had a negative impact on the generalizability of results. Below are some suggestions for future studies on this topic.

Inclusion of children from different age groups could yield valuable information about developmental progress in the acquisition of spatial language in Afrikaans. This would also make it possible to test the hypothesis that there is a developmental progression in the 
frequency of the different response types for PP+verb particle structures. If $\mathrm{PO}$ responses are indeed the least sophisticated of the three response types, it is likely that they would be used more by younger children; older children would be expected to use more CA and MA responses. It would also be interesting to see at which point PO responses would disappear from MA-speaking children's speech, given that these responses are not allowed in the speech of adult speakers of MA. Due to limitations of the present study in terms of participant numbers, the possibility of such a developmental progression for MA-speaking children could not be investigated.

Also, more research on the acquisition of spatial language by children with LI is needed; this study only included three such participants, and due to this small sample size as well as the general heterogeneity of children with specific language impairment, the contribution made by this study is limited. Future studies should also aim to include children with LI from nonmainstream dialects, as atypical errors in this population might differ from those of MAspeaking children with LI. Theoretical accounts for atypical errors of children with LI should also be explored further in future studies. The PP+particle verb structure examined in this study shows many similarities with directional PPs. It remains to be established whether these similarities in Afrikaans are only superficial, or whether they could be explained by a common underlying syntactic structure.

As a satellite-framed language with a rich adpositional system, more knowledge about how motion events are expressed in Afrikaans could provide interesting insights into the general study of spatial language. Crosslinguistic research could be valuable in this regard, either on narrative development in the vein of Berman and Slobin (1994) or on the expression of motion events in more controlled experimental situations (such as those reported by Ochsenbauer and Hickmann, 2010, in press; Laloi 2007; Bowermann 1996).

Such future research will expand the information on typical and atypical language development in Afrikaans-speaking children, potentially rendering findings useful for providing theoretical accounts of the expression of motion events as well as for clinical practice with Afrikaans children with language impairment.

\section{Notes}

1. Direction is also expressed by means of circumpositional and postpositional phrases (see e.g. Biberauer 2007, Oosthuizen 2000) which often seem superficially similar or even identical to the particle verb structure in sentence (2).

2. The item af can express at least two meanings: the first (translated as 'down') involves directional movement; the second (translated as 'off') involves separation of two entities and may, but need not, imply directional motion.

3. In Mainstream Afrikaans (MA), some prepositional constructions typically associated with a locative meaning can take on a directional meaning (Biberauer and Folli 2004). Sentence (i), for example, can be interpreted conventionally as expressing locative meaning (i.e. the boy is already inside the box and is jumping on the spot), but is also open to a directional meaning interpretation (i.e. the boy is jumping into the box). Sentence (ii) presents the circumpositional structure by means of which directional motion would typically be conveyed, although both options are grammatically acceptable in MA. 
(i) Die seun spring in die boks. the boy jumps in the box "He jumps in(to) the box"

(ii) Die seun spring in die boks in. the boy jumps in the box in "He jumps into the bath"

This ambiguity is most likely due to the properties of the motion verb together with which the pre- or circumpositional structure is used. It appears that if a sufficient degree of directed motion is already encoded in a given verb, an additional directional element such as a particle or postposition is optional (Biberauer and Folli 2004; see also Stringer 2006).

4. $\quad$ Note that, in (i), the second af might also be considered a postposition.

\section{References}

Bamberg, M. 1994. Development of linguistic forms: German. In R. Berman and D. Slobin (eds). Relating events in a narrative: a crosslinguistic developmental study. Hillsdale: Lawrence Erlbaum Associates Publishers. pp. 219-220.

Behrens, H. 1998. How difficult are complex verbs?: Evidence from German, Dutch and English. Linguistics 36(4): 679-712.

Berman, R. and D. Slobin. 1994. Relating events in a narrative: a crosslinguistic developmental study. Hillsdale: Lawrence Erlbaum Associates Publishers.

Biberauer, T. and R. Folli. 2004. Goals of motion in Afrikaans. In O. Courzet, H. Demirdache and S. Wauquier-Gravelines (eds). Proceedings of Journées d'Etudes Linguistiques (pp. 19-26.) Retrieved from http://www.lettres.univ-nantes.fr/aai/ on 28 June 2009.

Biberauer, T. 2007. Doubling and omission: insights from Afrikaans. In O. Crouzet, H. Demidarche and S. Wauquier-Gravelines (eds). Papers from the Workshop on Doubling in the Dialects of Europe. Amsterdam: Meertens On-line Publications. Retrieved from http://www.dialectsyntax.org/index.php/dialect-syntax-archive-mainmenu-66 on 23 May 2009.

Bloom, L. 1976. One word at a time: The use of single word utterances before syntax (3rd ed.). The Hague: Mouton.

Bowermann, M. 1996. Learning how to structure space for language: a crosslinguistic perspective. In P. Bloom, M. Peterson, L. Nadel and M. Garrett (eds). Language and Space. Cambridge: MIT Press. pp. 385-435.

Bowermann, M., and S. Choi. 2001. Shaping meanings for language: universal and languagespecific in the acquisition of spatial semantic categories. In M. Bowermann and S. Levinson (eds). Language acquisition and conceptual development. Cambridge: Cambridge University Press. pp. 474-511.

Choi, S. and M. Bowermann. 1991. Learning to express motion events in English and Korean: the influence of language-specific lexicalization patterns. Cognition 41: 83-121.

Clark, E. 1973. Non-linguistic strategies and the acquisition of word meanings. Cognition 2: $161-182$.

Den Dikken, M. 1992. Particles. Unpublished doctoral dissertation, University of Leiden.

Donaldson, B. 1993. A grammar of Afrikaans. Berlin: Mouton de Gruyter.

Grimm, H. 1975. On the child's acquisition of semantic structure underlying the wordfield of prepositions. Language and Speech 18(2): 97-119. 
Hickmann, M. 2006. The relativity of motion in first language acquisition. In M. Hickmann and S. Robert (eds). Space in languages: Linguistic systems and cognitive categories. Amsterdam: John Benjamins Publishing Company. pp. 281-307.

Hickmann, M., P. Taranne and P. Bonnet. 2009. Motion in first language acquisition: Manner and Path in French and English child language. Journal of Child Language 36: 705-741.

Huttenlocher, J., M. Vasilyeva and P. Shimpi. 2004. Syntactic priming in young children. Journal of Memory and Language 50: 182-195.

Kauschke, C. and C. Hofmeister. 2002. Early lexical development in German: a study on vocabulary growth and vocabulary composition during the second and third year of life. Journal of Child Language 29: 735-757.

Laloi, A. 2007. Role of universal and language-specific factors in the expression of motion by English- and French-speaking children. Unpublished Master's thesis, University of Amsterdam.

McIntyre, A. 2007. Particle verbs and argument structure. Language and Linguistics Compass 1(4): 350-367.

Nelson, K. 1974. Concept, word and sentence: interrelations in acquisition and development. Psychological Review 81(4): 267-285.

Ochsenbauer, A. and M. Hickmann (in press). How do German and French children express voluntary motion? Manuscript submitted for publication in C. Paradis, J. Hudson and U. Magnuson (eds). Conceptual spaces and the construal of spatial meaning. Empirical evidence from human communication. Oxford: Oxford University Press.

Ochsenbauer, A. and M. Hickmann. 2010. Children's verbalizations of motion events in German. Cognitive Linguistics 21(2): 217-238.

Oosthuizen, J. 2000. Prepositions left and right in Afrikaans. Stellenbosch Papers in Linguistics 33: 67-90.

Oosthuizen, H. 2009. Prepositions and verb particles in Afrikaans: dialectal variation and developmental patterns. Unpublished Master's thesis, University of Potsdam.

Ponelis, F.A. 1979. Afrikaanse sintaksis [Afrikaans syntax]. Pretoria: J.L. Van Schaik (Edms) Bpk.

Ramchand, G. and P. Svenonius. 2002. The lexical syntax and lexical semantics of the verbparticle construction. Retrieved from http://ling.auf.net//ling buzz/000007 on 20 September 2009.

Saint-Dizier, P. 2006. Introduction to the syntax and semantics of prepositions. In P. SaintDizier (ed.) Syntax and semantics of prepositions. Dordrecht: Springer. pp. 1-25.

Stone, G. 1995. The lexicon and sociolinguistic codes of the working-class Afrikaansspeaking Cape peninsula coloured community. In R. Mesthrie (ed.) Language and social history: Studies in South African sociolinguistics. Cape Town: David Philip Publishers (Pty) Ltd. pp. 277-290.

Stringer, D. 2006. Typological tendencies and universal grammar in the acquisition of adpositions. In P. Saint-Dizier (ed.) Syntax and Semantics of Prepositions. Dordrecht: Springer. pp. 57-68.

Strömqvist, S., H. Ragnarsdóttir and U. Richthoff. 2001. Input and production in the early development of function words. In J. Weissenborn and B. Höhle (eds). Approaches to bootstrapping: Phonological, lexical, syntactic and neurophysiological aspects of early language acquisition, Volume 2. Amsterdam: John Benjamins Publishing Company. pp. 157-177.

Talmy, L. 2000. Towards a cognitive semantics. Volume I: Concept structuring systems. Cambridge, MA: MIT Press. 
Tomasello, M. 1987. Learning to use prepositions: a case study. Journal of Child Language 14: 79-98.

Watkins, R. and M. Rice. 1991. Verb particle and preposition acquisition in languageimpaired preschoolers. Journal of Speech and Hearing Research 34: 1130-1141.

Wurmbrand, S. 2000. The structure(s) of particle verbs. Unpublished manuscript, McGill University. DOI:10.1.1.43.1300. 